\title{
Minority of doctors block CMA diversity overhaul
}

\author{
Cite as: CMAJ 2021 September 13;193:E1435-6. doi: 10.1503/cmaj.1095960
}

Posted on cmajnews.com on August 25, 2021.

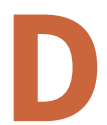
ebate over diversity and democratic processes dominated the Canadian Medical Association (CMA) annual general meeting held virtually on Aug. 22.

A small group of doctors defeated two motions aimed at boosting the inclusion of underrepresented groups in CMA leadership, and disputes cast a shadow over the ratification of the organization's first Indigenous president-elect, Dr. Alika Lafontaine.

The first motion proposed to allow all members to vote to select the CMA president-elect nominee. Historically, doctors in each Canadian jurisdiction have taken turns selecting a nominee in a local vote.

The second motion proposed to replace elections for CMA board and committee positions with a search committee that would recommend candidates based on an "evolving set of skills and diversity attributes." CMA had planned to appoint an inaugural search committee composed of three board members, three physician "members-at-large," and one nonphysician with experience in governance for an initial one-year term.

While most physicians at the meeting supported the leadership overhaul, the motions failed to win the two-thirds majority required to pass.

CMA Vice-Chair Dr. Carl Nohr presented the motions as part of an "intentional plan to diversify our leadership." To date, most CMA presidents have been white men, notably including the late Prince Philip, Duke of Edinburgh.

"While diversity and equity may happen by chance, they usually do not," Nohr explained. "Democracy always allows the majority to rule but ... if we wish to reflect diversity in leadership, we must design a governance model that intentionally lifts up minorities."

CMA developed the two motions in consultation with groups representing Black and Indigenous physicians, women in medicine and physicians with disabilities.

Incoming CMA President Dr. Katharine Smart supported expanding the vote for each president-elect nominee to members across Canada as a "chance for all members to get to know more about the individuals who may be representing them."

Dr. Onye Nnorom, president of the Black Physicians' Association of Ontario, applauded the proposals as "progressive." She noted the importance of changing systems to remove barriers to medical leadership for underrepresented groups. "These actions are in the right direction towards equal opportunity."

However, a group of physicians from British Columbia, including former presidents of national and provincial medical associations, opposed the motions, arguing that the CMA was trying to pass undemocratic changes under the guise of equity, diversity and inclusion efforts.

Leading up to the meeting, Drs. Granger Avery, Eric Cadesky, Alan Ruddiman, Charles Webb and others argued that existing processes were already promoting increasingly diverse candidates.

According to these physicians, "we have proven that when diverse candidates are mentored, encouraged to run and prepared for their campaigns then informed, intelligent members are capable of directly electing leaders that represent Canadian doctors."

Webb warned on social media that the proposed governance changes would see CMA directors appointed through a "behind door process" and give members in more populous provinces the "final say" in selecting CMA presidents.

Avery, a former CMA president, also pushed to postpone voting given that only 300 or so of the association's 86,000 members were present at the meeting.

However, other physicians attributed the recent successes of candidates from historically excluded groups to those individuals defying the odds.

"Those physicians had to learn to navigate a system that was designed to raise up leaders unlike them - a system that excluded many Canadian physicians," said Dr. Renee Fernandez, executive director of BC Family Doctors.

According to incoming president-elect Dr. Alika Lafontaine, the status quo "requires the excluded [and] disempowered to fully shoulder the burden of inclusion and change ourselves."

Housekeeping changes outlined in the CMA 2021 Report to Members were also defeated. These included tweaking language to reframe the role of the "general council" of delegates appointed by provincial and territorial medical associations as just "one body" among others guiding CMA policy.

While some physicians noted that it's normal to pass housekeeping amendments without unpacking the details of those changes, others expressed concerns about transparency.

Dr. Richard Merchant from New Westminster, BC, said he opposed the changes because he had "no idea what I'm voting for."

Tensions came to a head during the ratification of leadership nominations for board positions and the incoming president-elect.

Dr. Matthew Butcher, an Edmontonbased radiologist, opposed the ratification 
and called for the board's resignation for pushing "anti-democratic" changes.

Dr. Clover Hemans, past president of the Federation of Medical Women of Canada, urged her peers to support the nominations, noting that defeating the motion would also defeat "our opportunity to have our first Indigenous CMA president and that itself sends a particularly distasteful message."

"I'm sure the CMA Council and the board are well aware of the concerns that were made during this meeting, and they will need to take them into consideration when we next meet," Hemans added.

Ultimately, the motion ratifying the nominations passed with $87.5 \%$ in favour and $12.5 \%$ opposed.

Throughout the nearly four-hour meeting, there were delays, confusion and disruptions from a few physicians repeatedly making points of order and privilege.

Many physicians took to social media to express disappointment with the proceedings.

According to incoming CMA President Dr. Katharine Smart, "performative allyship took centre stage as we challenged the status quo."

Dr. Kim Kelly called it a "classic example of how power of the dominant group prevails and the systemic exclusion in medicine continues."

The procedural interruptions were particularly "in keeping with why there is a lack of true inclusion," tweeted Dr. Amy Tan. "Some know how to play the system to get what they want - rules written by and for them."
According to CMA Board Chair Dr. Suzanne Strasberg, the organization will "reflect, continue to listen to the feedback and adjust our approach." To that end, CMA will organize roundtable discussions on next steps to improve equity, diversity and inclusion, including a webinar with current and former presidents in September.

\section{Diana Duong, CMAJ}

Content licence: This is an Open Access article distributed in accordance with the terms of the Creative Commons Attribution (CC BY-NC-ND 4.0) licence, which permits use, distribution and reproduction in any medium, provided that the original publication is properly cited, the use is noncommercial (i.e., research or educational use), and no modifications or adaptations are made. See: https://creativecommons.org/ licenses/by-nc-nd/4.0/ 